\title{
Estabilização de solo arenoso com emulsão asfáltica para fins de pavimentação
}

\author{
Sandy soil stabilization with asphalt emulsion for paving purposes \\ Estabilización de suelos arenosos con emulsión asfáltica para pavimentación
}

Recebido: 02/12/2021 | Revisado: 07/12/2021 | Aceito: 15/12/2021 | Publicado: 01/01/2022

\author{
Lucas Fonseca Fernandes \\ ORCID: https://orcid.org/0000-0002-8720-9290 \\ Universidade Federal do Rio Grande do Norte, Brasil \\ E-mail: lucas.civil1996@gmail.com \\ Bruma Morganna Mendonça de Souza \\ ORCID: https://orcid.org/0000-0002-9766-8255 \\ University of New Hampshire, Estados Unidos \\ E-mail: bmorganna@gmail.com \\ Osvaldo de Freitas Neto \\ ORCID: https://orcid.org/0000-0001-9488-4123 \\ Universidade Federal do Rio Grande do Norte, Brasil \\ E-mail: osvaldo.neto@ufrn.br \\ Fagner Alexandre Nunes de França \\ ORCID: https://orcid.org/0000-0002-8113-622X \\ Universidade Federal do Rio Grande do Norte, Brasil \\ E-mail: fagnerfranca@ufrn.edu.br \\ Olavo Francisco dos Santos Júnior \\ ORCID: https://orcid.org/0000-0001-7552-6646 \\ Universidade Federal do Rio Grande do Norte, Brasil \\ E-mail: olavo.santos@ufrn.edu.br
}

\begin{abstract}
Resumo
O modal mais utilizado para o transporte de cargas e pessoas no Brasil é o rodoviário. Entretanto, por vezes, não há disponibilidade de materiais que atendam aos requisitos de pavimentação, enfatizando a necessidade de técnicas de estabilização dos solos para o ajuste do material às especificações desejadas. Assim, o objetivo deste trabalho foi avaliar o comportamento de uma areia siltosa bem-graduada (SM-SW), da cidade de Natal/RN, cujas características são incompatíveis para o uso no pavimento. Esta foi estabilizada com emulsão asfáltica de ruptura rápida (RR-2C). Foram realizados ensaios de Índice de Suporte Califórnia (ISC) e de Penetrômetro Dinâmico de Cone (DCP) em três teores de emulsão $(3 \%, 5 \%$ e $7 \%)$ e em três condições: sem cura e imersão; sem cura e com imersão; e com cura de 7 dias e imersão. Os resultados apontam uma redução da capacidade de suporte após mistura, embora as correlações entre ISC e DCP tenham apresentado ajustes mais adequados e melhores coeficientes de determinação $\left(\mathrm{R}^{2}\right)$, com valores superiores a 0,80. Além disso, após a cura, houve uma tendência de aumento dos valores de ISC, mas ainda assim a emulsão mostrou-se pouco eficaz na estabilização do solo para uso na base e sub-base de um pavimento.
\end{abstract}

Palavras-chave: Rodovias, Pavimentação, Solo, Estabilização, Emulsão.

\begin{abstract}
Highways are the most used modal for the transportation of cargo and people in Brazil. However, there is usually no availability of soils that meet pavement design criteria, emphasizing the need for soil stabilization techniques for material adjustments within the desired specifications. Therefore, this work aimed to evaluate the behavior of a wellgraded silty sand (SM-SW) from the city of Natal/RN, whose characteristics are unsatisfactory for paving. It was stabilized with fast-breaking asphalt emulsion (RR-2C). California Bearing Ratio (CBR) and Dynamic Cone Penetrometer (DCP) tests were performed in three emulsion contents $(3 \%, 5 \%$, and $7 \%$ ) under three conditions: without curing and without immersion; without curing and with immersion; and with 7 days cure and immersion. The results indicate a reduction in bearing capacity after mixing, even though the correlations between CBR and DCP have presented more adequate adjustments and improved coefficients of determination $\left(\mathrm{R}^{2}\right)$, with values superior to 0.80. Besides, after the curing process, there was an increase in the CBR values, but the emulsion has still proven to be low effective in stabilizing the soil for use as base and sub-base of a pavement.
\end{abstract}

Keywords: Highways, Paving, Soil, Stabilization, Emulsion.

\section{Resumen}

El modal más utilizado para el transporte de carga y personas en Brasil es la carretera. Sin embargo, por muchas veces, no hay disponibilidad de materiales que cumplan con los requisitos de pavimentación, enfatizando la necesidad de técnicas de estabilización del suelo para ajustar el material a las especificaciones deseadas. Así, el objetivo de este 
trabajo fue evaluar el comportamiento de una arena limosa bien graduada (SM-SW), de la ciudad de Natal / RN, cuyas características son incompatibles para su uso en el pavimento. Este se estabilizó con emulsión asfáltica de ruptura rápida (RR-2C). Las pruebas de California Bearing Ratio (CBR) y Dynamic Cone Penetrometer (DCP) se llevaron a cabo en tres contenidos de emulsión $(3 \%, 5 \%$ y $7 \%)$ y en tres condiciones: sin curado e inmersión; sin curar y con inmersión; y con cura e inmersión de 7 días. Los resultados apuntan a una reducción de la capacidad de carga tras la mezcla, aunque las correlaciones entre CBR y DCP han mostrado ajustes más adecuados y mejores coeficientes de determinación $\left(\mathrm{R}^{2}\right)$, con valores superiores a 0,80 . Además, después del curado, hubo una tendencia a que los valores de CBR aumentaran, pero aun así la emulsión demostró ser ineficaz para estabilizar el suelo para su uso en la base y subbase de un pavimento.

Palabras clave: Carreteras; Pavimentación; Suelo; Estabilización; Emulsión.

\section{Introdução}

Segundo Anuário CNT do Transporte (Confederação Nacional do Transporte, 2019), a malha viária brasileira é responsável por cerca de $60 \%$ do transporte de mercadorias no país e esse número é elevado para 90,0\% quando se fala no transporte de passageiros. A pesquisa, que percorreu 1.720 .700 quilômetros em estradas federais, estaduais e municipais, revela que apenas $12,4 \%$ das rodovias são pavimentadas e, o demonstrativo mais impactante, foi observado perante as condições dos pavimentos. Observou-se que 59,0\% da malha viária nacional apresenta alguma patologia e é classificada como regular, ruim ou péssima. Este número se eleva para 65,6\% quando analisado o estado do Rio Grande do Norte.

Bernucci et al. (2008) definem o pavimento de uma rodovia como uma estrutura de múltiplas camadas com espessuras bem definidas, executadas de modo a resistir aos esforços oriundos do tráfego de veículos e do clima, bem como propiciar aos usuários melhoria nas condições de rolamento, com conforto, economia e segurança.

É de conhecimento comum no meio técnico a significativa heterogeneidade dos solos, de sorte que é comum, nos projetos e implantação de obras de engenharia as condições dos solos do local não atenderem as características técnicas demandadas dos mesmos. Dessa forma, sobretudo em obras de pavimentação, por questões técnicas, econômicas, sociais e ambientais, tem-se buscado alternativas que empregam materiais alternativos à pavimentação convencional, o que torna imprescindível os estudos de estabilização dos solos.

A estabilização consiste no tratamento do solo por um processo mecânico ou químico, que torna o solo temporária ou permanentemente estável para os limites de sua utilização, mesmo sob a ação de cargas exteriores e ações climáticas (Batista, 1976). A estabilização do solo com ligante betuminoso pode ser feita a partir de cimento asfáltico de petróleo, asfalto diluído ou emulsão asfáltica, a forma mais empregada no Brasil (Pacheco, 2011).

Nesse contexto, surge também a possibilidade de uso de solos tropicais locais, que não se enquadram nas metodologias tradicionais de projeto e execução de pavimentos, visto que a as técnicas de ensaios e caracterização dos solos é oriunda de países de clima temperado e, por isso não levam em consideração as peculiaridades destes materiais (Miceli, Jr., 2006). Entretanto, quando analisados frente à metodologia MCT - Miniatura, Compactada Tropical, alguns solos que seriam rejeitados para fins de pavimentação, quando classificados à luz de metodologias tradicionais, podem apresentar bom desempenho (Nogami e Villibor, 1981; 1985; 1998 apud Santos, 2009).

Entende-se por estabilização ou melhoramento de solos qualquer processo, independente da natureza (física, química ou mecânica), com finalidade de modificar as propriedades originais do solo de modo que seu comportamento seja potencializado para devido uso, de modo a torná-lo apropriado para atender as exigências requeridas (Dias, 2012).

Santos (2012) define a estabilização física como a adição de material de modo que as propriedades do solo sejam alteradas e assim sua textura seja modificada. Este processo envolve basicamente a mudança de temperatura, hidratação (cimentação e endurecimento devido à hidratação de cimento Portland), evaporação (secagem de solos reforçados com betume emulsionado) e adsorção.

A estabilização mecânica trata-se do melhoramento do solo por meio de alterações na proporção das partes sólidas, 
líquidas e gasosas, sem que haja adição de qualquer tipo de material. Esta pode ser realizada por compactação e/ou procedimentos que alterem apenas o arranjo das partículas, de modo a aumentar a densidade do solo. (Santos, 2012).

Cruz (2004) define a estabilização química como a mistura do solo com outros materiais (agentes estabilizadores), que promovem reações químicas junto às partículas de sólidos e de água, o que permite obter um solo com características mais próximas daquelas que se pretendem para a sua utilização. Os agentes estabilizadores mais utilizados são: emulsão asfáltica, cimento Portland, cal e pozolanas.

A estabilização química promove não só melhorias nos parâmetros de resistência do solo, como também na redução da susceptibilidade de variação da umidade. Em função disso, este método é essencialmente utilizado em pavimentos rodoviários, nos quais o solo está submetido a situações mais severas, ora sob condições muito secas, ora sob condições de saturação (Cruz, 2004).

Dentro da temática supramencionada, afirma-se que este artigo tem o objetivo de avaliar a influência do teor de emulsão asfáltica na resistência de um solo tropical típico da cidade do Natal/RN, compactado sob energia normal e modificada, a partir dos ensaios de ISC e do DCP, com vistas a avaliar a possibilidade de uso dessa mistura (solo-emulsão) como base ou sub-base de um pavimento.

De acordo com a Associação Brasileira de Empresas Distribuidora de Asfaltos (2001), solo-emulsão é o produto decorrente da mistura de solos, geralmente locais, com emulsão asfáltica em geral, catiônica, na presença ou não de fíler mineral ativo.

Mattos (1991 apud Pacheco, 2011) afirma que a mistura solo-emulsão é um sistema heterogêneo, formado por três fases: duas descontínuas (solo e emulsão asfáltica) e uma contínua (água). O autor também afirma que, quanto maior a quantidade de água adicionada, mais lenta é a ruptura da emulsão asfáltica e melhor é a mistura. Entretanto, o mesmo chama a atenção para o cuidado com a quantidade de emulsão asfáltica adicionada à mistura, haja vista que após a compactação a emulsão asfáltica fecha rede capilar entre os grãos, que promove uma ação hidrófuga capaz de aumentar a resistência dos sistemas.

Pacheco (2011) ressalta a relevância do tempo de cura uma vez que é nessa etapa que ocorre o processo de evaporação de água da emulsão (contrário dos processos de cura convencionais), o que facilita a formação do filme de betume, que confere as características de resistência e impermeabilidade à mistura. Cada mistura possui um comportamento próprio, pois depende diretamente do tipo de solo com a qual a emulsão asfáltica foi misturada. Além disso, o teor de emulsão também implica diretamente no comportamento do solo.

\section{Metodologia}

\subsection{Localização da área de estudo e caracterização do solo estudado}

$\mathrm{Na}$ etapa experimental dessa pesquisa foram utilizados cerca de $250 \mathrm{~kg}$ de um solo arenoso, típico da cidade de Natal/RN o qual é frequentemente utilizado em obras rodoviárias na região. A coleta da amostra de solo foi realizada na zona

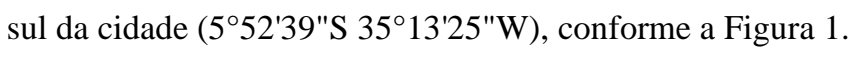


Figura 1: Localização da área de estudo no Rio Grande do Norte (a) e na cidade de Natal (b).

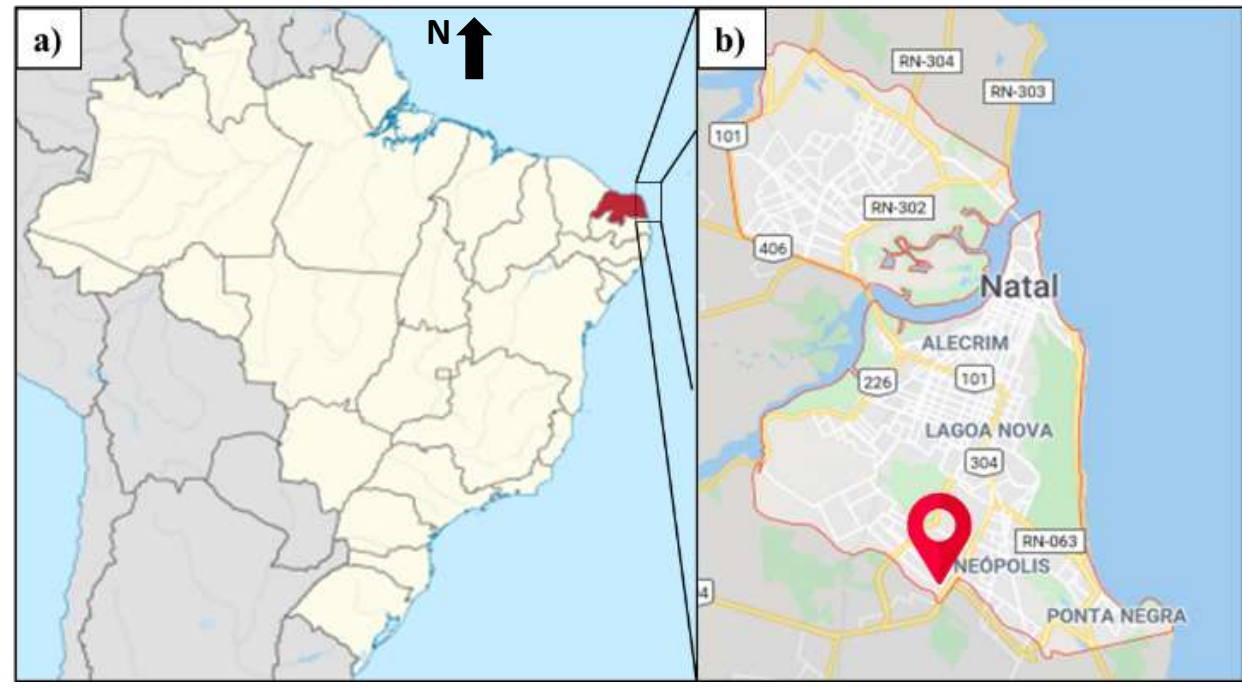

Fonte: Adaptado do Google Maps (2020).

Foram realizados ensaios para determinação do peso específico dos sólidos (NBR 6458:2016), limites de liquidez (NBR 6459:2016) e de plasticidade (NBR 7180:2016), bem como a granulometria por peneiramento e sedimentação (NBR 7181:2016). O solo não apresentou limite de plasticidade nem limite liquidez e a massa específica dos sólidos foi de 2,69 $\mathrm{g} / \mathrm{cm}^{3}$. A Figura 2 apresenta a curva granulométrica do solo estudado o qual foi classificado de acordo com o Sistema Unificado de Classificação de Solo (SUCS) como areia siltosa bem graduada (SW-SM) e de acordo a classificação rodoviária (TRB) da AASHTO (Association of State Highway Transportation Officials) como A-2-4.

Figura 2: Curva granulométrica do solo.

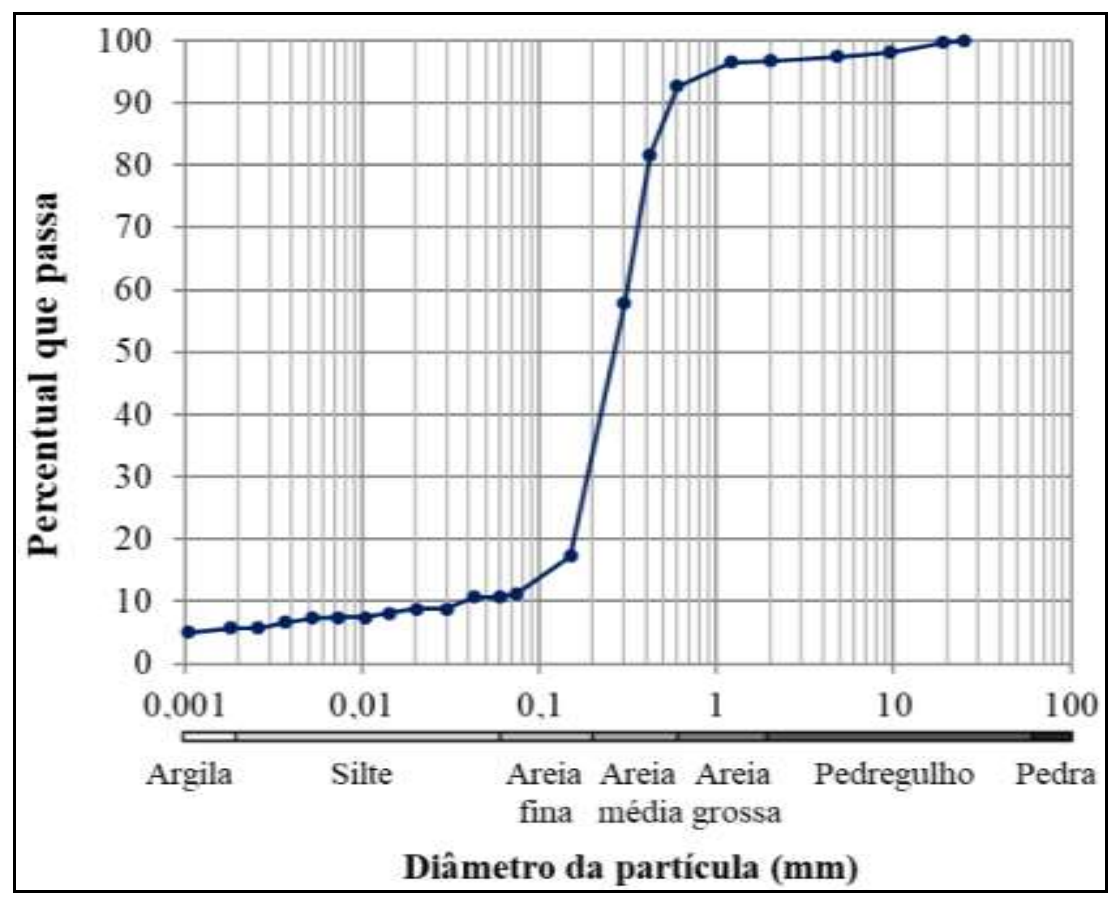

Fonte: Adaptado de Souza (2019). 


\subsection{Caracterização da emulsão asfáltica}

A emulsão asfáltica utilizada durante a pesquisa foi do tipo ruptura rápida, de carga elétrica de partícula positiva (emulsão catiônica RR-2C), cuja propriedades foram obtidas a partir de ensaios realizados por um laboratório especializado. Os resultados encontram-se na Tabela 1.

Tabela 1: Características da Emulsão Asfáltica.

\begin{tabular}{cccc}
\hline Ensaio & Unid. & Especificação & Resultado \\
\hline Viscosidade Saybolt-Furol a $25^{\circ} \mathrm{C}$ & Seg. & $100-400$ & 390 \\
Sedimentação, 5 dias & $\%$ massa & 5 máx. & 0,31 \\
Penetração, 0,84 mm & $\%$ massa & 0,1 máx. & 0 \\
Carga da partícula & - & Positiva & Positiva \\
Resíduo seco & $\%$ massa & 67 min. & 67,4 \\
Desemulsibilidade & $\%$ massa & 50 min. & 67 \\
\hline
\end{tabular}

Fonte: Autores (2020).

\subsection{Preparo da mistura solo-emulsão}

Neste trabalho foi avaliada a influência do teor de emulsão na mistura, de sorte que nesta pesquisa, foram adotados os teores de emulsão equivalentes a 3\%,5\% e 7\% em relação a massa do material, conforme sugerido por na literatura para a estabilização de solos de características semelhantes (GONDIM, 2008; SANTOS, 2009). Com as amostras de solo e de soloemulsão preparadas, foram realizados ensaios de compactação à energia normal e energia modificada. A partir dos resultados dos ensaios de compactação foram obtidos parâmetros para preparar os corpos de prova para a realização dos ensaios de ISC e DCP, os quais foram realizados com os corpos de prova preparados no teor de umidade ótimo.

Com relação à água adicionada, parte foi misturada inicialmente somente com o solo, água de dispersão $\left(\mathrm{A}_{\text {disp }}\right)$ e parte foi diluída na emulsão, água de diluição $\left(\mathrm{A}_{\mathrm{dil}}\right)$. Santos (2009) explica que tal procedimento é necessário, pois o solo é considerado um material hidrófilo e a adição da emulsão diretamente no solo seco, acelera o processo de ruptura da emulsão.

Para determinar a quantidade de água que foi adicionada para se atingir um determinado teor de umidade foram utilizadas as Equações de 1 a 7. A fim de corrigir o teor de umidade do solo, inicialmente na condição de umidade higroscópica para o teor de umidade de interesse, o primeiro passo foi adicionar ao solo o volume de água equivalente à água de dispersão. Em seguida adicionou-se à emulsão a água de diluição e, em seguida, a emulsão já diluída foi incorporada e homogeneizada.

$\left.1^{\circ}\right)$ Determinação da massa de solo seco de amostra $\left(M_{d}\right)$ :

$M_{\text {d }}=M_{w} /\left(100+w_{\text {hig }}\right)$

Em que: “ $w_{\text {hig }}$ " é a umidade higroscópica em percentual e " $M_{w}$ "é a massa de solo sob umidade higroscópica.

$\left.2^{\circ}\right)$ Determinação da quantidade de emulsão $\left(M_{e m}\right)$ calculada em relação ao solo seco:

$M_{\text {em }}=\%$ de emulsão $\cdot M_{d}$

$3^{\circ}$ ) Determinação da quantidade de água contida na emulsão $\left(A_{e m}\right)$ :

$$
A_{\text {em }}=(100-\% \text { de CAP na emulsão }) \cdot M_{\text {em }}
$$

$\left.4^{\circ}\right)$ Determinação da quantidade de água total a adicionar $\left(A_{t a d}\right)$ para obtenção de determinada umidade:

$A_{\text {tad }}=\left(w-w_{\text {hig }}\right) \cdot M_{d} / 100$

Em que: " $w$ " é umidade que se deseja obter.

$\left.5^{\circ}\right)$ Determinação da quantidade de água a ser acrescentada à mistura $\left(A_{m}\right)$ :

$A_{\mathrm{m}}=A_{\text {tod }}-A_{\text {em }}$

$\left.6^{\circ}\right)$ Determinação da água de diluição $\left(A_{d i l}\right)$ : 
$A_{\text {dil }}=M_{\text {em }}$

$\left.7^{\circ}\right)$ Determinação da água de dispersão $\left(A_{\text {disp }}\right)$ :

$A_{\text {disp }}=A_{\text {tad }}-\left(A_{\text {dil }}+A_{\text {em }}\right)$

\subsection{Ensaios realizados com a mistura solo-emulsão}

Os ensaios de compactação da mistura solo-emulsão, nos três teores de emulsão adotados $(3 \%, 5 \%, 7 \%)$, foram realizados à luz da norma ABNT NBR 7182:2016 (Solo - Ensaio de compactação), com o objetivo de se obter a curva de compactação e a partir dela extrair o teor de umidade ótimo nas energias normal e modificada, respectivamente. Os resultados obtidos nos ensaios subsidiaram a preparação dos corpos de prova para realização dos ensaios de Índice de Suporte Califórnia ISC (NBR 9895:2016) e Dynamic Cone Penetration - DCP normatizado pela ASTM D-6951:2018 (Figura 3)

Os ensaios de ISC e DCP nas misturas (solo + emulsão) compactadas nas energias normal e modificada foram realizados sob as seguintes condições de cura: rompimento logo após moldagem sem imersão (ensaio sem cura e sem imersão); rompimento após imersão de 96 horas (ensaio sem cura e com imersão); e rompimento após 7 dias de cura mais imersão de 96 horas (ensaio com cura de 7 dias e com imersão). Os resultados dos ensaios realizados nas misturas (solo + emulsão) foram comparados com os resultados do solo puro.

Após a moldagem dos corpos de prova, os mesmos foram armazenados com objetivo de proteger contra impactos e vibrações, além de permitir a evaporação de água. De acordo com Pacheco (2011) esta evaporação de água da emulsão facilita a formação do filme de betume, o que confere as características de resistência e impermeabilidade à mistura.

Figura 3: Penetrômetro dinâmico de cone (DCP).

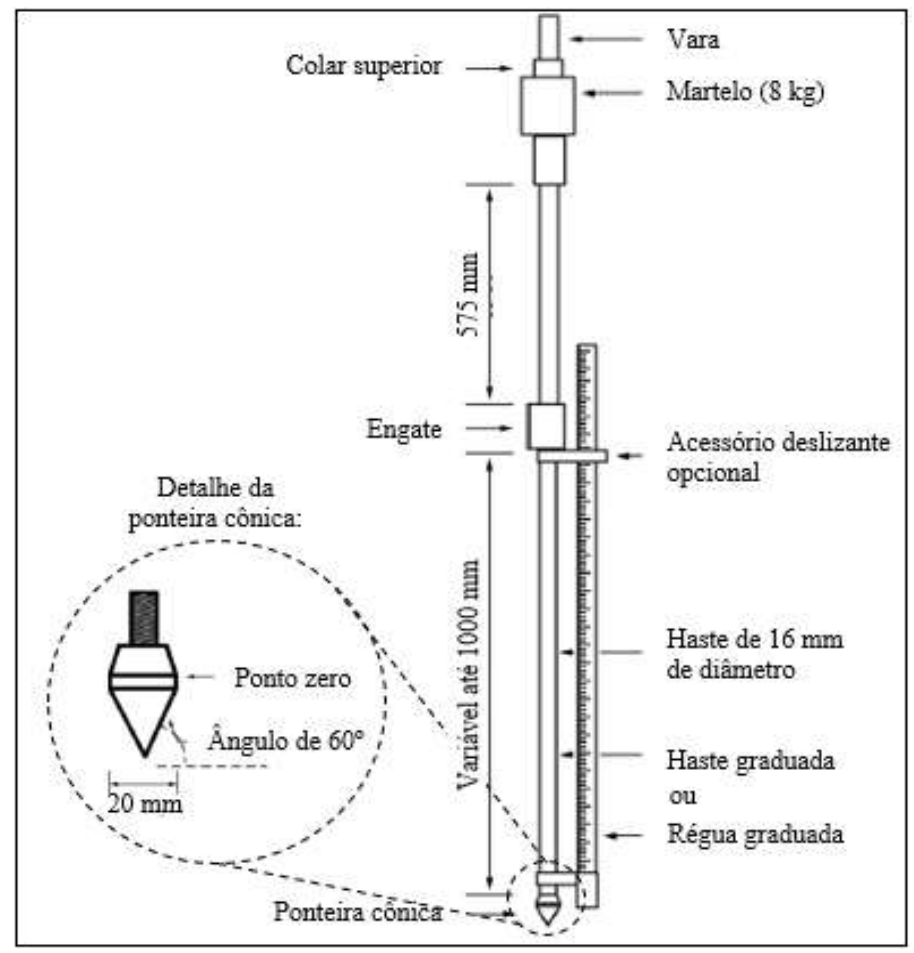

Fonte: Adaptado da ASTM (2018).

Diversos estudos apontam uma correlação direta entre DCP e ISC, de modo que a partir do valor do DCP estime-se o valor de ISC. Esses estudos surgem da necessidade de se determinar o valor de ISC, o qual ainda é o método mais utilizado 
para avaliar o comportamento dos solos para a pavimentação, de forma mais rápida e fácil, haja vista que demanda mais tempo e infraestrutura, quando comparado ao DCP. Dessa forma, o DCP tem sido amplamente utilizado para fins de pavimentação e tem se apresentado uma ferramenta prática e de baixo custo para a estimativa o ISC e consequentemente para a avaliação estrutural.

Carvalho (2005) alerta que grande parte das correlações publicadas não menciona as condições de realização dos ensaios, das características dos materiais empregados, do número de testes realizados e nem dos valores dos coeficientes de determinação das equações encontrados, de modo que o uso indiscriminado de tais correlações pode implicar em erros significativos. Assim deve-se chamar a atenção para as limitações e restrições no uso de correlações disponibilizadas na literatura, uma vez que até solo com mesma classificação, mas origens distintas podem apresentar comportamentos completamente diferentes (Souza, 2019).

Alves (2002) afirma que as equações que correlacionam DCP e ISC apresentam-se nas formas de potência (Equação 8) e logarítmica (Equação 9), em que o ISC é dado em porcentagem e o DCP em mm/golpe. Nestas equações, a constante "A” representa parâmetros relativos à massa do martelo, altura de queda e restituição do aço do penetrômetro dinâmico de cone e a constante "B" representa as perdas no sistema.

$$
\begin{aligned}
& C B R=A \times D C P^{B} \\
& \log (C B R)=\log (A)+B \times \log (D C P)
\end{aligned}
$$

\section{Resultados e Discussão}

\subsection{Compactação do solo e da mistura solo-emulsão}

As Figuras 4 e 5 apresentam as curvas de compactação nas energias normal e modificada, respectivamente, do solo puro e das misturas solo-emulsão nos teores de 3\%, 5\% e 7\% de emulsão. A Tabela 2 apresenta o resumo dos ensaios de compactação, com os valores de teor de umidade ótimo e a massa específica aparente seca máxima para cada uma das misturas nas diferentes energias de compactação, extraídas das curvas de compactação.

Figura 4: Curvas de compactação na energia normal.

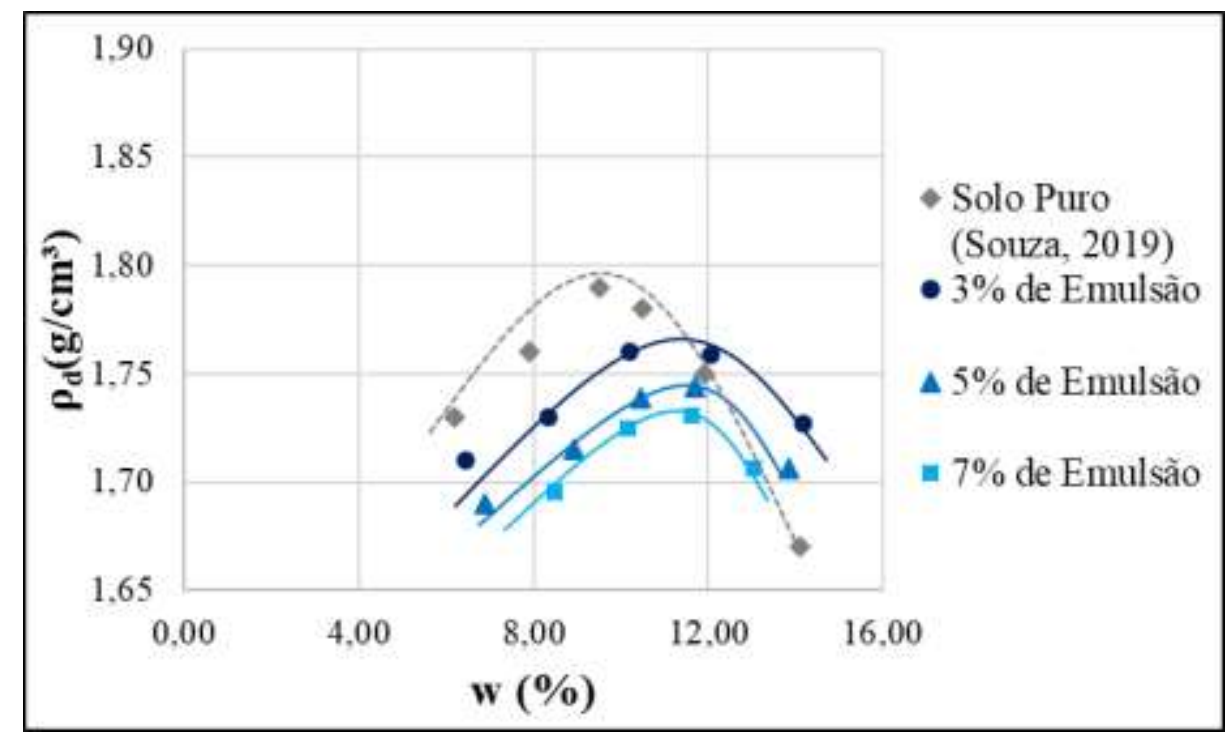

Fonte: Autores (2020).

Figura 5: Curvas de compactação na energia modificada. 


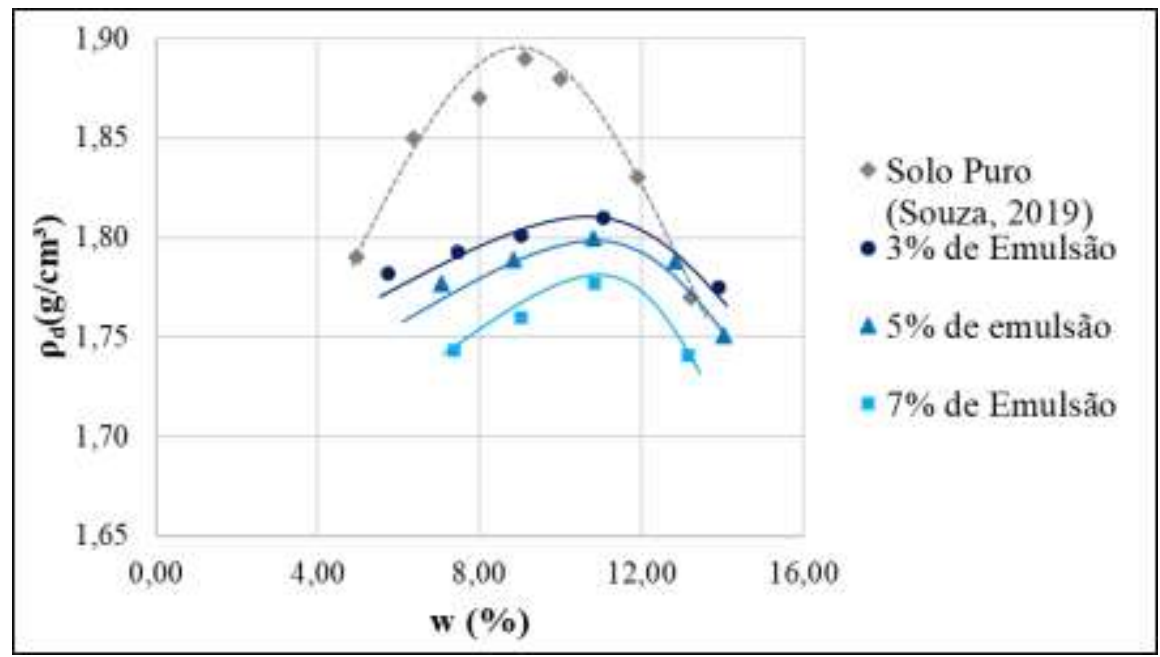

Fonte: Autores (2020).

Tabela 2: Resultados dos ensaios de compactação.

\begin{tabular}{cccc}
\hline Energia de compactação & Teor de Emulsão $(\boldsymbol{\%})$ & $\boldsymbol{w}_{\text {ot }}(\boldsymbol{\%})$ & $\boldsymbol{\rho}_{\boldsymbol{d}}\left(\mathbf{g} / \mathbf{c m}^{\mathbf{3}}\right)$ \\
\hline \multirow{3}{*}{ Energia Normal } & 0,0 & 9,6 & 1,80 \\
& 3,0 & 12,0 & 1,76 \\
& 5,0 & 11,7 & 1,75 \\
& 7,0 & 11,5 & 1,74 \\
\hline \multirow{3}{*}{ Energia Modificada } & 0,0 & 9,1 & 1,90 \\
& 3,0 & 11,1 & 1,81 \\
& 5,0 & 10,8 & 1,80 \\
& 7,0 & 10,8 & 1,78 \\
\hline
\end{tabular}

Fonte: Autores (2020).

A partir das curvas de compactação, observou-se que a mistura solo-emulsão em ambas energias de compactação, de maneira geral, apresentou teores de umidade ótimo mais elevados que o solo puro, e que a massa especifica aparente seca menores que do solo puro, o que provocou um deslocamento das curvas para baixo e para direita.

Os resultados também mostram um decréscimo do valor da massa específica aparente seca máxima com o aumento de teor de emulsão asfáltica, de modo que este decréscimo foi mais significativo no conjunto de ensaios de compactação realizados com a energia modificada. Além disso, percebe-se um aumento no teor de umidade ótimo das misturas em relação ao solo puro. Entretanto, o teor de umidade ótimo pouco varia entre misturas com teores de emulsão distintos.

Este resultado contrapõe-se aos resultados encontrados na literatura, em que o teor de umidade ótimo da mistura soloemulsão costuma ser menor que do solo puro, sendo essa variação menor que $1 \%$ e por isso pode ser desconsiderada na maioria dos casos (Lucena et al.,1982; Araújo et al., 1983; Momm, 1983). De fato, percebe-se que a variação do teor de umidade ótimo das misturas, apenas, não passa da margem apresentada na literatura (1\%). O que chama atenção é o aumento inicial da umidade ótima, que ocorreu tanto na energia normal quanto na energia modificada. Tal comportamento poderia ser creditado ao tipo de emulsão asfáltica utilizada nessa pesquisa (RR-2C), enquanto que na literatura foram encontrados apenas estudos com emulsão do tipo RL e RM.

$\mathrm{O}$ incremento do teor de umidade ótimo observado pode ser justificado em função da água presente na emulsão asfáltica e da água utilizada para sua diluição. Isso porque durante a mistura do solo com o ligante, embora o resultado final seja homogêneo, não há uma completa adesão entre as partículas de solo e a emulsão, haja vista que o tipo utilizado não 
facilita a homogeneização. Observou-se também que a mistura, para todos os teores de umidade do ensaio, aparentemente estava mais seca do que seu real valor de umidade, uma vez que parte da água não estava de fato misturada ao solo e sim presa na emulsão.

A massa específica aparente seca máxima, por sua vez, à medida que se aumentou o teor de emulsão, tendeu a diminuir cerca de 1,0\%. De acordo com Santos (2009) tal comportamento é esperado haja vista que o menor valor da densidade da emulsão em relação ao solo. Por mais que até certo ponto a emulsão atue como de aglutinante, o que pode facilitar a compactação, esta passa a ocupar parte considerável do volume de solo ensaiado, o qual antes era apenas solo, o que torna a amostra mais leve.

\section{2 Índice de Suporte California (ISC)}

De acordo com o Manual de Pavimentação (DNIT, 2006), a camada de subleito de um pavimento deve apresentar ISC mínimo de $2 \%$, o reforço de subleito deve ter ISC obrigatoriamente maior que do material do subleito, a sub-base deve apresentar ISC mínimo de $20 \%$ e a base deve apresentar ISC mínimo de $80 \%$, mas materiais com ISC de $60 \%$ podem ser aceitos, desde que justificado economicamente pelo material disponível.

Os ensaios foram realizados nas energias normal e modificada, no teor de umidade ótimo de compactação e nas condições: sem cura e sem imersão, sem cura e com imersão, com cura de 7 dias e com imersão. A Tabela 3, apresenta os resultados obtidos no ensaio de ISC tanto para a mistura solo-emulsão quanto para o solo puro.

Tabela 3: Resultados dos Ensaios de ISC.

\begin{tabular}{ccccc}
\hline \multirow{2}{*}{$\begin{array}{c}\text { Energia de } \\
\text { compactação }\end{array}$} & $\begin{array}{c}\text { Teor de } \\
\text { Emulsão (\%) }\end{array}$ & $\begin{array}{c}\text { Sem cura sem } \\
\text { imersão }\end{array}$ & $\begin{array}{c}\text { Cem cura com } \\
\text { imersão }\end{array}$ & $\begin{array}{c}\text { Cura de 7 dias e } \\
\text { imersão }\end{array}$ \\
\hline \multirow{2}{*}{ Energia } & 0,0 & $16,90 \%$ & $14,21 \%$ & $0,00 \%$ \\
Normal & 3,0 & $8,83 \%$ & $5,92 \%$ & $4,41 \%$ \\
& 5,0 & $2,91 \%$ & $2,74 \%$ & $4,14 \%$ \\
& 7,0 & $1,78 \%$ & $2,04 \%$ & $2,78 \%$ \\
\hline \multirow{2}{*}{ Energia } & 0,0 & $38,54 \%$ & $22,85 \%$ & $0,00 \%$ \\
Modificada & 3,0 & $12,59 \%$ & $7,32 \%$ & $9,15 \%$ \\
& 5,0 & $7,21 \%$ & $6,78 \%$ & $6,89 \%$ \\
& 7,0 & $5,00 \%$ & $3,55 \%$ & $5,49 \%$ \\
\hline
\end{tabular}

Fonte: Autores (2020).

Os resultados mostram uma redução significativa dos valores de ISC quando misturada a emulsão ao solo, isto é, quanto maior o teor de emulsão misturada, menor o valor de ISC. Isso era esperado a partir das curvas de compactação, visto que a mistura solo-emulsão apresentou valores de massa específica seca aparente máxima inferiores aos do solo puro. Isso corrobora para o que afirma Gondim (2008) que diz que para menores teores de betume as misturas tendem apresentar maior resistência, logo maior capacidade de suporte.

Percebe-se que para energia normal, apesar da redução dos valores de ISC, a mistura-solo-emulsão poderia ser utilizada apenas para camada de subleito e talvez de reforço de subleito, assim como o solo puro, com ressalva para as misturas com $5 \%$ e $7 \%$ de emulsão, que apresentaram valores muito próximo ao limite permitido.

O mesmo não acontece na energia modificada, em que a mistura de emulsão não só provocou redução dos valores de ISC como também reduziu a aplicabilidade do material, posto que o solo puro poderia ser utilizado para camada de sub-base e as misturas, em todos os teores analisados, poderiam ser utilizadas apenas para camada de subleito e reforço de subleito. 
As amostras que foram submetidas a imersão apresentaram valores ainda mais baixos, pois as reações de ruptura da emulsão asfáltica sofrem influência da perda de água. Uma vez que a água entra em contato com a mistura solo-emulsão, a aderência entre o betume e a superfície das partículas do solo, que já é pequena, é desfeita, o que reduz ainda mais a capacidade de suporte das misturas (Gondim, 2008).

Rebelo (2009), observou que as misturas solo-emulsão estudadas foram prejudicadas pela imersão, em que os valores de ISC apresentaram-se inferiores àqueles alcançados pelas amostras com o solo sem emulsão. Gondim (2008), ao analisar os resultados de ensaios de ISC, observou que as amostras de solo-emulsão, se comportaram de maneiras distintas em presença de água, o que indica que a aderência entre a emulsão asfáltica e as partículas de solo diferiu. Em alguns casos, a emulsão provocou melhoria após imersão e em outros casos provocou redução na capacidade de suporte. Logo, não há um comportamento único para as misturas solo-emulsão após imersão. Tal comportamento depende diretamente do solo com o qual está se faz a mistura e por isso é necessário estudar cada mistura-solo emulsão individualmente.

Ao analisar as amostras submetidas ao processo de cura antes da imersão, com exceção da amostra de 3\% de emulsão na energia normal, nota-se que houve menor perda da capacidade de suporte do que as amostra que não passaram pelo processo de cura, isto é, as amostras curadas apresentaram valores de ISC mais elevados do que as amostras não curadas, ambas após imersão. Isso ocorre pois durante o processo de cura, as amostras perdem umidade, o que confere maior resistência, mesmo que este não tenha sido tão significativo em função do tempo de cura de apenas 7 dias.

\subsection{Ensaios de DCP e correlações com o ISC}

Os ensaios de DCP e ISC foram realizados nos mesmos corpos de prova, moldados e submetidos às mesmas condições de cura. Em todas as análises feitas não foi possível obter uma dispersão de pontos significativa ao longo da curva de correlação; isto é, só foram obtidos pontos que se iniciam em torno de $30 \mathrm{~mm} / \mathrm{golpe}$ no eixo das abscissas. Devido à falta de pontos experimentais para valores menores que $30 \mathrm{~mm} / \mathrm{golpe}$, o ramo inicial da curva, delimitado com uma linha contínua mais fina, foi feito por meio da extrapolação a partir dos resultados obtidos. Entretanto vale ressaltar, que o trecho extrapolado não foi considerado nas análises, mesmo com os altos valores dos coeficientes de determinação $\left(\mathrm{R}^{2}\right)$.

A Figura 6 apresenta os resultados encontrados para a condição sem cura e sem imersão, tanto para o solo puro quanto para a mistura solo-emulsão. A figura apresenta também uma faixa de resultados de correlações encontradas na literatura, de acordo com Souza (2019).

Os resultados mostram que o solo puro, apesar de apresentar uma alta correlação, com $\mathrm{R}^{2}$ igual a 0,94, apresenta uma curva fora da margem estabelecida a partir de outros estudos. A mistura solo-emulsão por sua vez apresenta um comportamento mais semelhante aos outros materiais, embora sua resistência seja menor do que a do solo puro. Além disso, a mistura solo-emulsão apresentou coeficiente de determinação pouco maior que o solo puro, o que pode indicar uma melhor correlação e um melhor comportamento. Isso sugere um efeito estabilizante da emulsão no solo, mesmo que a mistura tenha apresentado menores resistências nos ensaios de ISC e DCP.

Outro ponto a ser observado a partir da Figura 6 é que a correlação do solo puro que obteve melhor ajuste foi na forma de potência, enquanto o melhor ajuste para a mistura foi na forma logarítmica. Ambos são os tipos de ajustes mais utilizados na literatura, conforme Equações 8 e 9. A boa correlação apresentada pela mistura, legitimada pelo alto coeficiente de determinação, pela curva com comportamento semelhante a outros materiais e pelo ajuste na forma logarítmica, também corrobora para validar o uso do DCP em misturas de solo-emulsão. Para a condição sem cura e com imersão, a mistura soloemulsão teve comportamento similar à condição sem cura e sem imersão no que se refere a melhoria na correlação, conforme Figura 7. 
Figura 6: Correlação DCP x ISC de amostras sem cura e sem imersão.

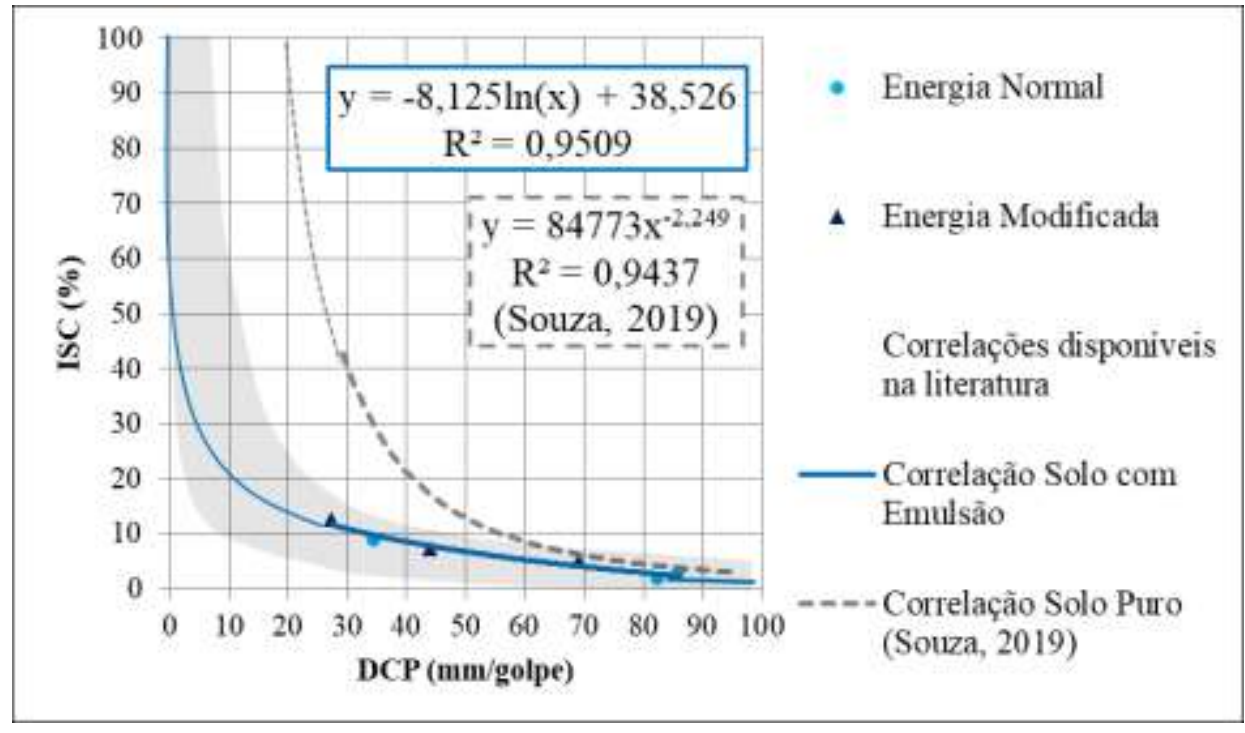

Fonte: Autores (2020).

Figura 7: Correlação DCP x ISC de amostras sem cura e com imersão.

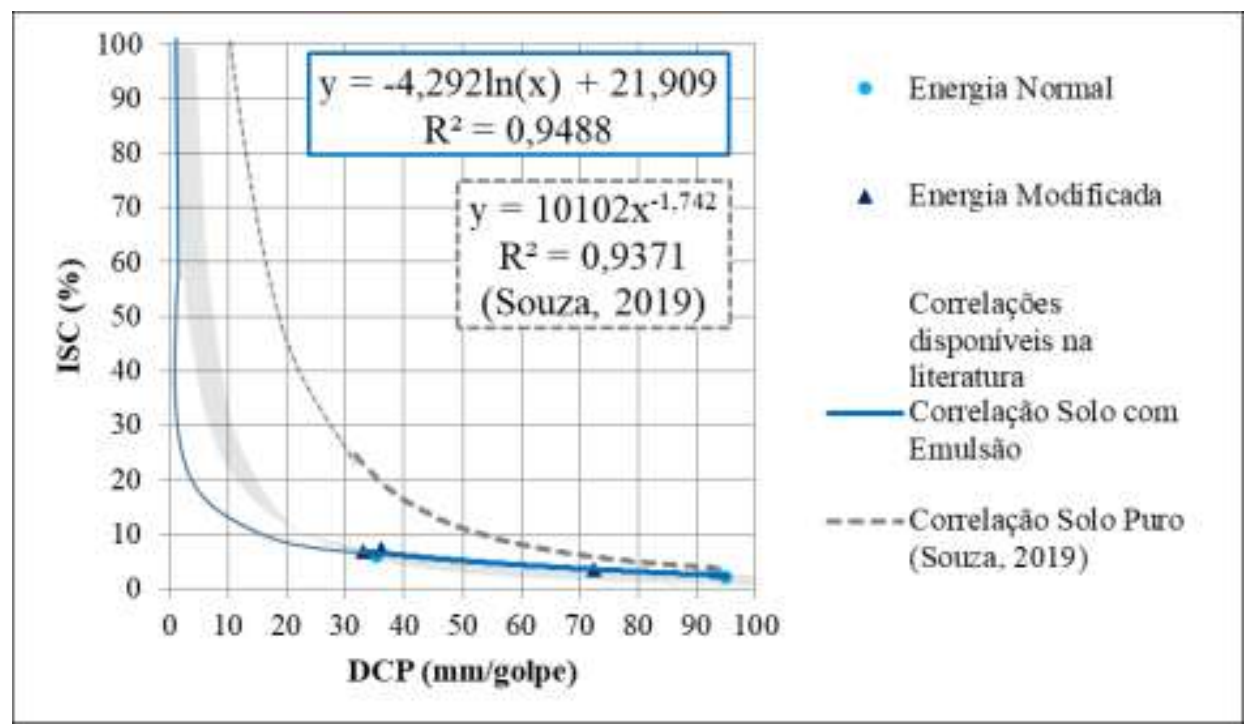

Fonte: Autores (2020).

Assim como na primeira condição (sem cura e sem imersão), a mistura sem cura, mas submetida à imersão, apresentou um coeficiente de determinação mais elevado que a correlação do solo puro, além de um comportamento que se aproxima um pouco mais da faixa de valores da literatura, apresentados por Souza (2019). Além disso, o melhor ajuste também foi obtido na forma logarítmica.

Outro ponto perceptível a partir da análise dos resultados é que a mistura segue um mesmo padrão do solo puro no que se refere à qualidade dos resultados, isto é, tanto para o solo puro quanto para a mistura o coeficiente de determinação foi mais alto para a condição em que não houve imersão.

Para fins de comparação foi também estabelecida uma correlação levando em consideração todos os resultados obtidos (Figura 8) e o resultado mostra uma redução do coeficiente de determinação em relação ao solo puro, mas ainda assim alcançando valores superiores a 0,85. Além disso, a mistura que para as correlações anteriores apresentou o melhor ajuste na 
forma logarítmica, nesta correlação o melhor ajuste foi na forma de potência. Por outro lado, a mistura solo-emulsão, apresentou uma correlação que se encaixa na faixa de valores da literatura.

Figura 8: Correlação DCP x ISC considerando todos os pontos.

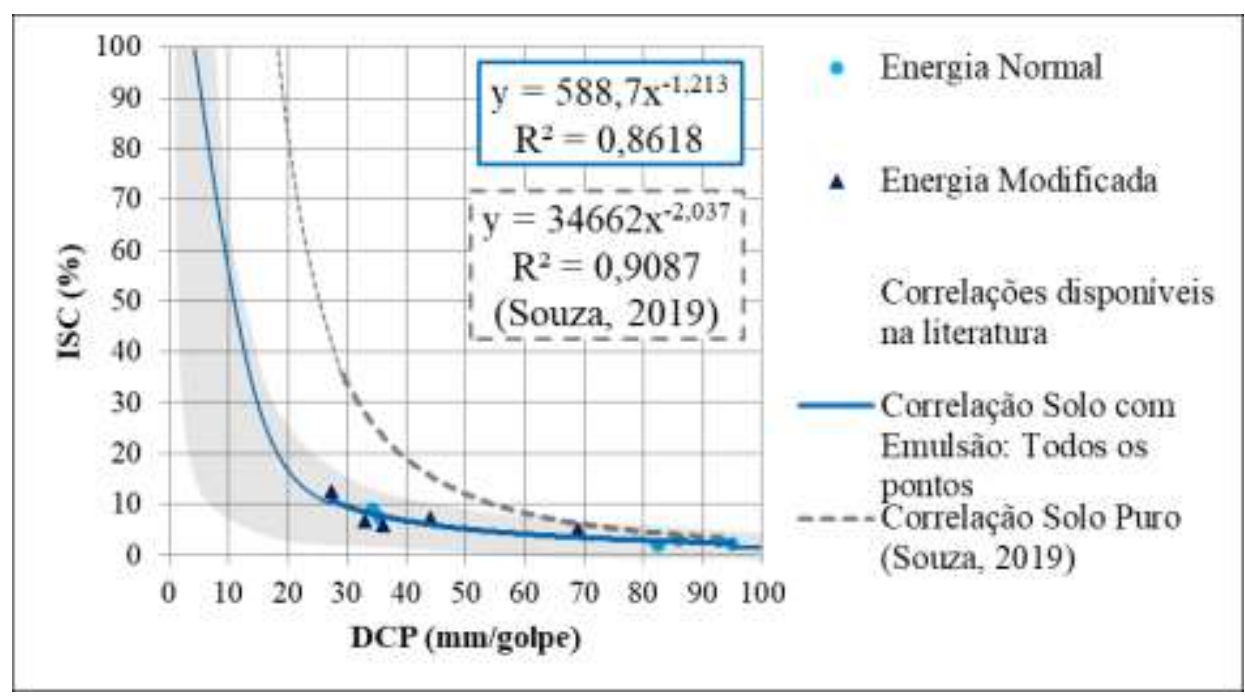

Fonte: Autores (2020).

Por fim, foi obtida uma correlação considerando o efeito da cura após sete dias, conforme Figura 9. Assim como na correlação considerando todos os pontos, o melhor ajuste foi na forma de potência. Nesse caso o coeficiente de determinação, embora tenha sido acima de 0,80 , foi o menor dentre as correlações analisadas. Percebe-se que tanto os pontos correspondentes aos corpos de prova compactados com energia modificada quanto com energia normal, se concentraram em determinadas regiões, de forma que qualquer variabilidade, mínima que seja, fora do ajuste torna-se um grande desvio e por isso faz reduzir o coeficiente de determinação.

A Figura 10 apresenta todas as correlações estabelecidas com a mistura solo-emulsão nesse estudo, bem como a correlação após cura de sete dias, comparadas a correlação existente na norma ASTM 6951:2018 para todos os tipos de solo.

Percebe-se então que o comportamento da mistura solo-emulsão é bem parecido em todas as condições analisadas, mesmo que apresentem ajustes diferentes para algumas dessas condições. Além disso, também se nota que o comportamento da mistura está mais próximo ao comportamento previsto na norma ASTM 6951:2018, quando comparado ao solo puro. No entanto, fica evidente a redução na capacidade de suporte da mistura, posto que o solo puro se obteve pontos no gráfico próximos a $30 \%$ de ISC e a mistura não chegou nem a $50 \%$ desse valor.

Assim, pode-se afirmar que as correlações obtidas para a mistura solo-emulsão são satisfatórias, tanto pelos ajustes na forma logarítmica e de potência, conforme cita a literatura, quanto pelos elevados coeficientes de determinação.

Figura 9: Correlação DCP x ISC de amostras após cura e imersão. 
Research, Society and Development, v. 11, n. 1, e0711124274, 2022

(CC BY 4.0) | ISSN 2525-3409 | DOI: http://dx.doi.org/10.33448/rsd-v11i1.24274

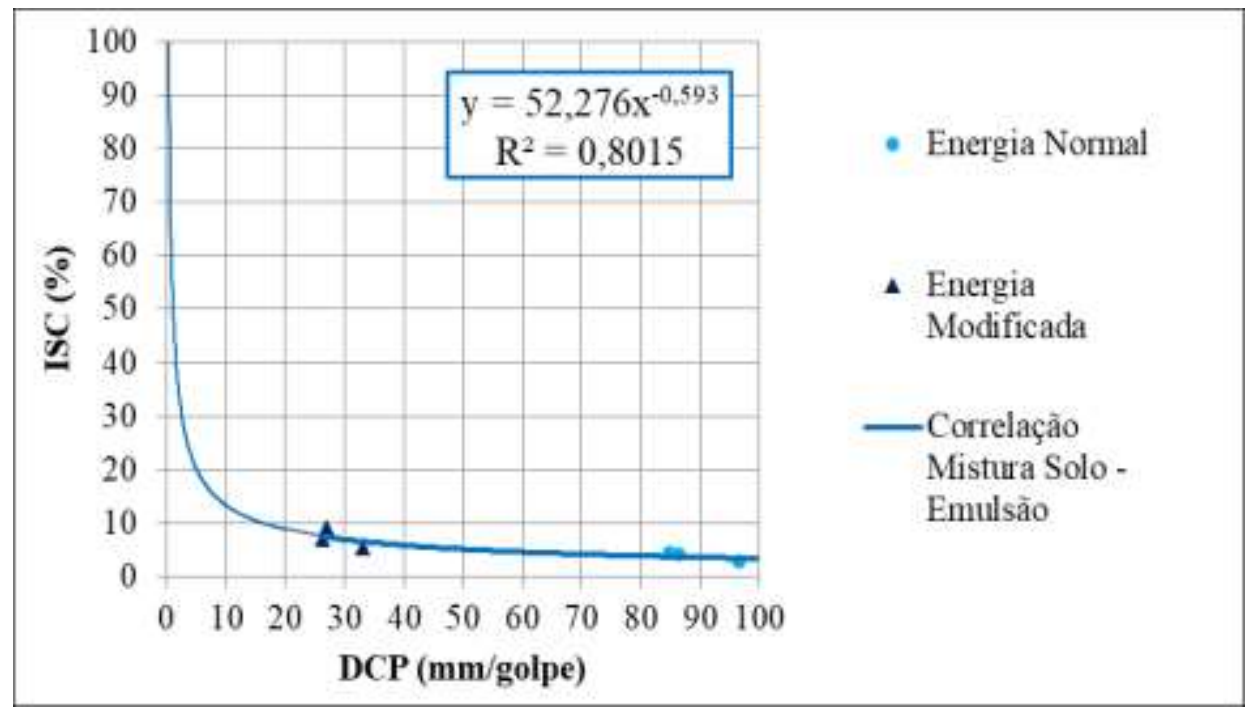

Fonte: Autores (2020).

Figura 10: Todas as correlações desenvolvidas para mistura.

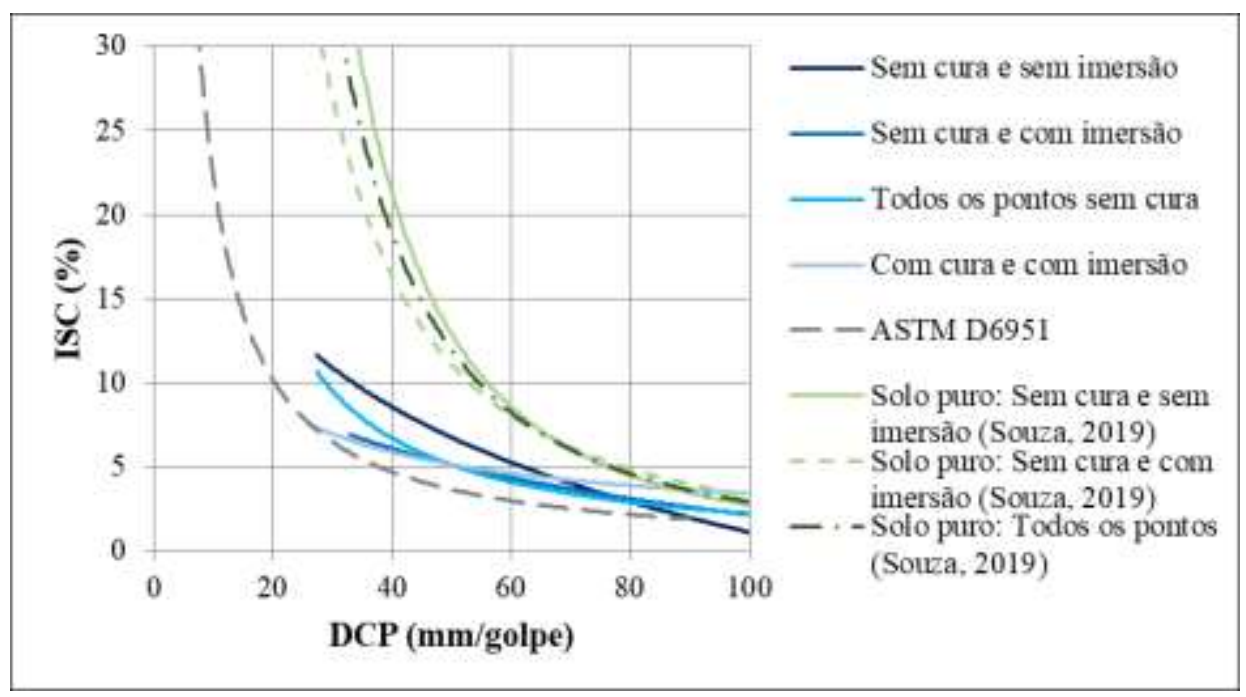

Fonte: Autores (2020).

\section{Conclusão}

A estabilização do solo tem o objetivo de promover melhorias das mais diversas formas em solos cujas características não se adequam ao exigido para os mais variados fins de engenharia. Os resultados da mistura foram comparados com o do solo puro e a partir deles é possível concluir que:

- O uso de emulsão asfáltica RR-2C para estabilizar o solo estudado, não foi satisfatório para uso na base e subbase de um pavimento, uma vez que os dados coletados mostram que a capacidade de suporte das misturas soloemulsão, em todas as condições de ensaio e teor de emulsão, foi inferior ao ISC indicado por norma para uso nas camadas de base e sub-base;

- Com o aumento do teor de emulsão asfáltica na mistura, a capacidade de suporte diminuiu, tanto no tocante à trabalhabilidade, pois observou-se dificuldade na homogeneização da mistura, quanto da menor densidade da emulsão em relação ao solo, que provoca uma menor compactação da mistura; 
- As misturas apresentaram correlações mais satisfatórias entre DCP e ISC do que o solo puro, que pode ser atestado pelos elevados coeficientes de determinação $\left(\mathrm{R}^{2}\right)$ pouco maiores que os do solo puro e pelo ajuste das linhas de tendência estabelecidas.

- O processo de cura para mistura solo-emulsão é de grande importância, uma vez que após a cura de 7 dias, a capacidade de suporte foi aumentada na maior parte das amostras, com exceção da mistura com $3 \%$ de emulsão realizado na energia normal, mas ainda assim não foram maiores que as capacidades de suporte do solo puro;

- A dificuldade da mistura do solo com a emulsão não só reflete no comportamento mecânico da mistura como também inviabiliza esse procedimento em campo.

Sugere-se para o desenvolvimento de trabalhos futuros o uso da emulsão asfáltica de ruptura lenta e que sejam realizados estudos com outros tipos de solos, com granulometrias diferentes, avaliando outros percentuais de emulsão asfáltica e tempo de cura de até 28 dias.

\section{Agradecimentos}

Os autores agradecem o apoio da CAPES (Coordenação de Aperfeiçoamento de Pessoal de Nível Superior) e ao Programa de Pós-Graduação em Engenharia Civil da UFRN para desenvolvimento desse trabalho científico.

\section{Referências}

Alves, A. B. C. (2002). Avaliação da capacidade de suporte e controle tecnológico de execução da camada final de terraplenagem utilizando o penetrômetro dinâmico de cone. 171f. Dissertação (Mestrado em Engenharia Civil) - Universidade Federal de Santa Catarina, Florianópolis.

American Society for Testing and Materials. ASTM. D6951/D6951M (2018): Standard Test Method for Use of the Dynamic Cone Penetrometer in Shallow Pavement Applications. West Conshohocken.

Associação Brasileira das Empresas Distribuidoras de Asfaltos - ABEDA (2001). Manual Básico de Emulsões Asfálticas - Soluções para pavimentar sua Cidade, Rio de janeiro.

Associação Brasileira de Normas Técnicas. NBR 6458 (2016). Grãos de pedregulho retidos na peneira de abertura 4,8 mm - Determinação da massa específica, da massa específica aparente e da absorção de água. Rio de Janeiro.

Associação Brasileira de Normas Técnicas. NBR 6459 (2016). Solo - Determinação do limite de liquidez. Rio de Janeiro.

Associação Brasileira de Normas Técnicas. NBR 7180 (2016). Solo-Determinação do limite de plasticidade. Rio de Janeiro.

Associação Brasileira de Normas Técnicas. NBR 7181 (2016). Solo - Análise granulométrica. Rio de Janeiro.

Associação Brasileira de Normas Técnicas. NBR 7182 (2016). Solo - Ensaio de compactação. Rio de Janeiro.

Associação Brasileira de Normas Técnicas. NBR 9895 (2016). Solo - Índice de suporte Califórnia (ISC) - Método de ensaio. Rio de Janeiro.

Balbo, J. T. (2007). Pavimentação asfáltica: Materiais, projeto e restauração. São Paulo: Oficina de Textos.

Batista, C. F. N. (1976). Ensaios fundamentais para a pavimentação e dimensionamentos dos pavimentos flexíveis. V.1, $2^{\mathrm{a}}$ ed. Porto Alegre: Globo.

Benevides, L. D. (2012). Avaliação do uso do DCP em areias para controle da capacidade de carga em fundações diretas e controle de compactação de aterros. Dissertação (Mestrado em Engenharia Civil) - Universidade Federal do Rio Grande do Norte, Natal, Rio Grande do Norte.

Bernucci, L. B, Motta, L. M. G, Ceratti, J. A. P \& Soares, J. B. (2008). Pavimentação asfáltica: Formação básica para engenheiros. Petrobrás, Rio de Janeiro.

Carvalho, R. G (2005). Correlações entre os ensaios DCP e ISC para solos saprolíticos de textura fina. Dissertação (Mestrado em Engenharia de Infraestrutura) - Instituto Tecnológico de Aeronáutica, São José dos Campos.

Confederação Nacional do Transporte. (2019) Anuário CNT do transporte. https://anuariodotransporte.cnt.org.br/2019//> .

Cruz, M. L. S. (2004). Novas tecnologias da aplicação de solo-cimento. Dissertação (Mestrado em Engenharia Civil) - Universidade do Minho, Guimarães.

Departamento Nacional de Infraestrutura de Transporte. DNIT (2006). Manual de pavimentação. Instituto de Pesquisas Rodoviárias, Rio de Janeiro.

Dias, J. J. F. M. S. (2012) Tratamento de solos com cimento para obtenção de melhores características mecânicas. Dissertação (Mestrado em Engenharia Civil) - Universidade Nova de Lisboa, Caparica, 2012. 
Research, Society and Development, v. 11, n. 1, e0711124274, 2022

(CC BY 4.0) | ISSN 2525-3409 | DOI: http://dx.doi.org/10.33448/rsd-v11i1.24274

Gondim, L. M. (2008). Estudo experimental de misturas solo-emulsão aplicado às rodovias do agropólo do baixo Jaguaribe/estado do Ceará. Dissertação (Mestrado em Engenharia de Transportes) - Universidade Federal do Ceará, Fortaleza.

Lucena, F. B, Ferreira, H. C \& Araújo, R. N. A. (1982). Uso de Emulsão Catiônica na Estabilização de Solos Lateríticos. Anais da $17^{a}$ Reunião Anual de Pavimentação. Brasília, DF.

Miceli Júnior, G (2006). Comportamento de solos do estado do Rio de Janeiro estabilizados com emulsão asfáltica. Dissertação (Mestrado em Engenharia de Transportes) - Instituto Militar de Engenharia, Rio de Janeiro.

Momm, L. (1983) Uso de Emulsão Catiônica na Estabilização de Solos. Anais da 18a Reunião Anual de Pavimentação. Porto Alegre, RS.

Pacheco, L. M. (2011). Solos estabilizados com emulsão asfáltica para uso em pavimentação: estudo laboratorial. Monografia (Graduação em Engenharia Civil) - Universidade Federal do Rio Grande do Sul, Escola de Engenharia, Departamento de Engenharia Civil, Porto Alegre.

Rebelo, E. P. (2009). Estudo de mistura solo-emulsão para a região de Urucu (CoariAM). Dissertação (Mestrado em Engenharia Civil) - Curso de Engenharia Civil, Universidade Federal do Amazonas, Manaus.

Santos, M. N. (2012) Análise do Efeito da Estabilização Mecânica em Matrizes de Terra. Relatório de iniciação científica - Pontifícia Universidade Católica, Rio de Janeiro.

Santos, W. J. (2009). Avaliação do uso de emulsão asfáltica na estabilização química de três solos de Sergipe. Dissertação (Mestrado em Engenharia Civil e Ambiental) - Universidade Federal de Campina Grande, Centro de Tecnologia e Recursos Naturais, Campina Grande.

Souza, B. M. M. (2019). Estudo de correlação entre os índices de DCP e ISC de solos típicos da cidade de Natal/RN. Monografia (Graduação em Engenharia Civil) - Universidade Federal do Rio Grande do Norte, Centro de Tecnologia, Natal. 